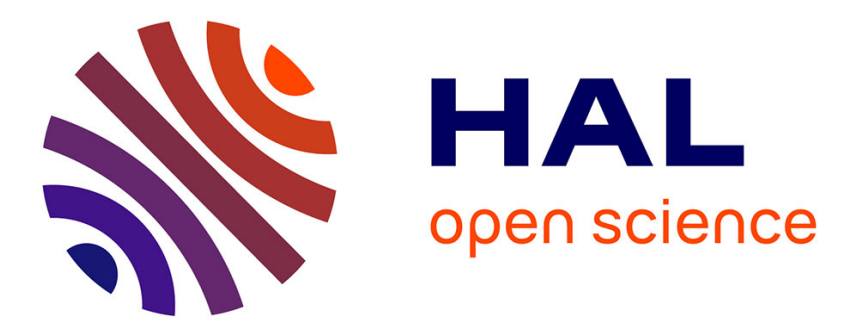

\title{
Electron microscopy investigations on highly beam and moisture sensitive samples - the system Li-Ba-Ca
}

\author{
Volodymyr Smetana, Arndt Simon, Viola Duppel, Lorenz Kienle
}

\section{To cite this version:}

Volodymyr Smetana, Arndt Simon, Viola Duppel, Lorenz Kienle. Electron microscopy investigations on highly beam and moisture sensitive samples - the system Li-Ba-Ca. Journal of Inorganic and General Chemistry / Zeitschrift für anorganische und allgemeine Chemie, 2009, 636 (2), pp.325. 10.1002/zaac.200900335 . hal-00534150

\section{HAL Id: hal-00534150 \\ https://hal.science/hal-00534150}

Submitted on 9 Nov 2010

HAL is a multi-disciplinary open access archive for the deposit and dissemination of scientific research documents, whether they are published or not. The documents may come from teaching and research institutions in France or abroad, or from public or private research centers.
L'archive ouverte pluridisciplinaire HAL, est destinée au dépôt et à la diffusion de documents scientifiques de niveau recherche, publiés ou non, émanant des établissements d'enseignement et de recherche français ou étrangers, des laboratoires publics ou privés. 


\section{Electron microscopy investigations on highly beam and moisture sensitive samples - the system Li-Ba-Ca}

\begin{tabular}{|c|c|}
\hline Journal: & Zeitschrift für Anorganische und Allgemeine Chemie \\
\hline Manuscript ID: & zaac. 200900335.R1 \\
\hline Wiley - Manuscript type: & Article \\
\hline $\begin{array}{r}\text { Date Submitted by the } \\
\text { Author: }\end{array}$ & 24-Sep-2009 \\
\hline Complete List of Authors: & $\begin{array}{l}\text { Smetana, Volodymyr; Max-Planck-Institut für Festkörperforschung } \\
\text { Simon, Arndt; Max-Planck-Institut für Festkörperforschung } \\
\text { Duppel, Viola; Max-Planck-Institut für Festkörperforschung } \\
\text { Kienle, Lorenz; Institut für Materialwissenschaft Universität Kiel }\end{array}$ \\
\hline Keywords: & electron microscopy, HRTEM, lithium, barium, calcium \\
\hline
\end{tabular}

\section{S scholaroNE" \\ Manuscript Central}


Electron microscopy investigations on highly beam and moisture sensitive samples the system Li-Ba-Ca

\title{
Lorenz Kienle, Volodymyr Smetana, Viola Duppel, and Arndt Simon*
}

\begin{abstract}
Max-Planck-Institut für Festkörperforschung, Heisenbergstrasse 1, D-70569 Stuttgart, Germany Dedicated to Professor Hans-Jörg Deiseroth on the occasion of his $65^{\text {th }}$ birthday
\end{abstract}

\begin{abstract}
The system Li-Ba-Ca was investigated by transmission electron microscopy. Three different phases could be identified and characterized. The crystal structure of the previously known compound $\mathrm{Li}_{33.3} \mathrm{Ba}_{13.1} \mathrm{Ca}_{3}$ was confirmed, however, variable $\mathrm{Ca}$ contents were observed in distinct crystallites. The same holds for phases with $\mathrm{BaLi}_{4}$ - and $\mathrm{Ba}_{19} \mathrm{Li}_{44}$-type structure, respectively. Structural transformations under irradiation occurred which were different for the crystallites of the $\mathrm{Li}_{33.3} \mathrm{Ba}_{13.1} \mathrm{Ca}_{3}$ - and $\mathrm{Ba}_{19} \mathrm{Li}_{44}$-types.
\end{abstract}

\section{Introduction}

In recent years, numerous binary and ternary compounds between alkali and alkaline earth elements have been reported: two modifications of $\mathrm{CaLi}_{2}$ [1-2], two compounds in the systems Sr-Li [3], Ba-Li [4-5], and Na-Ba [6-7], respectively. Further investigations indicated that ternary compounds between these elements also exist. Some of them were found in the systems $\mathrm{Li}-\mathrm{Na}-\mathrm{Ba}$ [8-9] and Li-Ba-Ca [9] displaying complicated X-ray powder diagrams due to very large lattice parameters and multicomponent character. Additionally, the single crystals exhibit complicated features like intergrowth and twinning, thus inhibiting detailed X-ray investigations. Further characterizations call for the diverse electron microscopy techniques (diffraction, imaging, spectroscopy) since they enable a local structure analysis, e.g. inside the single domains of a strongly intergrown crystal. However, the combination of extreme air 
sensitivity and low melting/ decomposition temperatures of the intermetallic phases under consideration seem to serve insurmountable experimental problems. We are not aware of investigations which overcome these problems by standard procedures easily, thus, our observations in the system Li-Ba-Ca mark a significant progress in the field of electron microscopy performed on samples highly relevant for solid state chemistry . 


\section{Experimental and methods}

The investigations involved an electron microscope CM 30ST (Philips, LaB 6 cathode, accelerating voltage: $300 \mathrm{kV}$ ), equipped with an EDX system (Noran, Vantage System). The diffraction and high resolution images were recorded with a multiscan CCD camera (Gatan). The samples were ground and inserted into the TEM under argon using a self constructed transfer system [10]. EDX analysis confirmed the functionality of such equipment, since only marginal O-K $\alpha$ intensities occurred, so that a hydrolysis of the sample due to contact with air could be excluded. The low melting temperatures of the intermetallic phases led to the actual experimental challenge. TEM was not possible with conventional settings, but only with an optimized beam diameter (spot 5-6) minimizing the dose in the region of interest. Despite such low-dose settings relatively short exposure times up to 1 s need to be selected in the case of high-resolution images. Another breakthrough for the investigation of air sensitive samples is given by the precession electron diffraction technique (PED) [11-15]. The PED technique with the electron beam moving on a precession cone (precession angle of $3^{\circ}$ ) minimizes multiple scattering and beyond that is superior to selected area electron diffraction (SAED, fixed beam), since the PED experiments overcome the time consuming adjustment of the precise zone axis orientation of the sample. The software Emaps was used to simulate PED diagrams [16].

Due to the beam sensitivity the following protocol for the characterization of the phases was followed: a) Search for selected (single phase) areas by bright field contrast, b) EDX analysis, c) raw adjustment of zone axis orientation by SAED, d) analysis by PED, e) observation by high resolution microscopy and f) EDX analysis.

Fourier transformations of high-resolution images have been calculated with the program CRISP [17]. All high-resolution images were Fourier filtered by use of a suitable mask (software Digital Micrograph 3.6.1, Gatan). Simulations of high-resolution images are based on the multi-slice method [18-19] with the aid of the EMS program package [20] $\left(\mathrm{C}_{\mathrm{s}}=1.15\right.$ $\mathrm{mm}, \Delta=7 \mathrm{~nm}, \alpha=1.2 \mathrm{mrad})$. 


\section{Results and Discussion}

In spite of the experimental challenges mentioned above, high-resolution images clearly show the structural motifs of the expected heavy-atom structure, such as characteristic clusters when performing the experiments under low-dose settings. The majority of the investigated crystallites showed a microstructure of differently oriented grains of one chemical component, hence, the interpretation of images and electron diffraction patterns was complicated by superposition.

The investigated sample was heterogeneous with three main components, $\mathrm{Li}_{33.3} \mathrm{Ba}_{13.1} \mathrm{Ca}_{3}$, and crystallites with domains assigned to the $\mathrm{Ba}_{19} \mathrm{Li}_{44}$-type and $\mathrm{BaLi}_{4}$-type, respectively. In accordance with X-ray examinations, EDX analyses and electron diffraction (cf. characteristic differences in the lattice constants) the Ca content in all phases varies. Firstly we observed a ternary alkali - alkaline earth intermetallic compound with domains of the $\mathrm{Ba}_{19} \mathrm{Li}_{44}$ type.

An example of SAED and PED diagrams of the steps c) and d) (cf. experimental section) are shown in Fig. 1a and b, respectively. The SAED pattern is of low quality with respect to resolution and the equilibration of the reflection intensities. The latter is based on multiple scattering even not allowing the doubtless identification of the Laue symmetry. Note, that reflections from higher order Laue zones (HOLZ) were not observed in the SAED diagram. In the PED diagram (Fig. 1b) the multiple scattering is minimized, thus, the identification of the different components of an inhomogeneous sample is possible, because in addition to the lattice parameters also the intensities may be used as reference. This is especially useful in the presence of complex phases, as the resolution in the PED pattern is considerably higher and intensities from HOLZ are present which represent fingerprints of the complex structures.

The PED diagram in Fig. 1b has a clear differentiation of the reflection intensities. The narrow sequence of reflections at high resolution based on a superposition of different Laue zones shows clearly the relatively large lattice parameters, which were expected for the $\mathrm{Li}_{33.3} \mathrm{Ba}_{13.1} \mathrm{Ca}_{3}$ structure type. It can be confirmed by a simulation of the PED diagram, cf. Fig. $1 c$.

In all crystallites of this type unexpectedly high $\mathrm{Ba}$ :Ca ratios were found after a short period of irradiation. The EDX analysis of the crystal characterized in Fig. 1 shows a ratio of ca. 7.8, significantly higher as compared to the ratio from X-ray analysis, ca. 4.4. However, it should 
be noted that the electron beam exposure, particularly in the nanoprobe-mode could distort analytical results. However, comparison of EDX analyses before and after long irradiation show only a slight increase in the Ba:Ca ratio. The d-values from Fig. 1a indicate a structure with higher Ba:Ca ratio $(\mathrm{d}(015)=12.31 \AA$ and $\mathrm{d}(10-2)=15.92 \AA)$, compared to $12.47 \AA$ and $16.11 \AA$ for the crystal with lower $\mathrm{Ba}$ Ca ratio from the X-ray analysis. In other grains variations of $\mathrm{Ba}: \mathrm{Ca}$ ratios have been observed, which, however, were always smaller than expected from the X-ray analysis.

Since the lithium content in the sample could not be determined by EDX analysis, the interpretation of varying $\mathrm{Ba}: \mathrm{Ca}$ content is still incomplete. It can be assumed that through increased occupation of the mixed $\mathrm{Li} / \mathrm{Ca}$ positions by $\mathrm{Li}$ atoms crystallites with a relatively high Li-content exist and thus the reduced lattice parameters can be rationalized. Synthetic work must clarify whether such homogeneity regions can be realized in thermodynamically stable products, and the details of the atomic distribution must be determined by single crystal $\mathrm{X}$-ray analysis.

The PED diagrams of some grains could be clearly assigned to the $\mathrm{Ba}_{19} \mathrm{Li}_{44}$-type (Fig. 2). The EDX analysis shows, however, the presence of $\mathrm{Ca}$. As a rule a larger $\mathrm{Ba}$ :Ca atomic ratio than that of the crystallites with the $\mathrm{Li}_{33.3} \mathrm{Ba}_{13.1} \mathrm{Ca}_{3}$ type structure was found. Furthermore the composition of the $\mathrm{Ba}_{19} \mathrm{Li}_{44}$ type grains varies and the presence of $\mathrm{Ca}$ leads to the contraction of the crystal lattice. The PED diagram taken along [110] (Fig. 2) yields $d(001)=16.04 \AA$ and $\mathrm{d}(-110)=11.38 \AA$ and thus somewhat smaller values than for pure $\mathrm{Ba}_{19} \mathrm{Li}_{44}(16.36 \AA$ and 11.59 $\AA$ ). Note the superposition of different Laue zones in the PED diagram of Fig. $2 \mathrm{~b}$ and the good agreement between experimental and simulated patterns.

Against all expectations, high quality HRTEM micrographs could be recorded under special conditions, particularly when the crystals are in close contact with the copper grid, however, time-consuming experiments, like the recording of complete focus series were not possible. Fig. 3 shows examples for the $\mathrm{Li}_{33.3} \mathrm{Ba}_{13.1} \mathrm{Ca}_{3}$ type. In Fig $3 \mathrm{a}$ the projection of the crystal potential along the zone axis [100] is shown with the high values correlating with the Ba atoms reproduced as bright dots. The obtained high resolution images are dominated by these heavy atoms, while the $\mathrm{Li}$ atoms have a negligible contribution to the potential and thus appear like vacancies in the structure. Along [100] $\mathrm{Li}$ and $\mathrm{Ba} / \mathrm{Ca}$ atoms are maximally separated, and the high-resolution images 3c (right) show good agreement with the simulations (Fig 3c, left) and 
prove the assignment of this domain to the $\mathrm{Li}_{33.3} \mathrm{Ba}_{13.1} \mathrm{Ca}_{3}$ type. The comparison with Fig $3 \mathrm{a}$ and $b$ corroborate the assumption that in the focus conditions of Fig 3c low values of the projected potential, associated with the Li substructure shows up as dark points. The observed periodic pattern with the broad dark contrasts is characteristic for the arrangement of the icosahedral $\mathrm{Li}_{13}$ clusters. The heavy atoms correlate with the bright spots. In underfocus (Fig $3 \mathrm{c}$, below left) the image resolution is increased, and the simulated micrograph is in quite good agreement.

The beam sensitivity of the crystallites with $\mathrm{Li}_{33.3} \mathrm{Ba}_{13.1} \mathrm{Ca}_{3}$-type structure depends heavily on this zone axis orientation. For [-25-1] (cf. Fig. 4) there is a much lower beam sensitivity, so that more extended focus series can be obtained. However, the interpretation of the images is complicated by a much more complex superposition of the atoms along the zone axis, as indicated by the bright spots (heavy atoms) in the projected potential map of Fig 4a. Such complexity is well reflected by the HRTEM micrographs. For $\Delta \mathrm{f}=-40 \mathrm{~nm}$ (Fig $4 \mathrm{~b}$ ) the contrast-transfer conditions of Scherzer focus ${ }^{21}$ are already observable. High values of the projected potential are indicated as black dots which form aggregates (see marks in Fig 4a, b) correlating with the heavy atom positions. For $\Delta \mathrm{f}=-70 \mathrm{~nm}$ the contrast is inverted, so that these heavy atoms are seen as white spots. Even with further defocusing $(\Delta \mathrm{f}=-90 \mathrm{~nm})$ high quality images could be observed with considerably more detailed structural information. The excellent agreement with the simulations emphasize that in this zone axis orientation the decomposition by electron beam impact is relatively low. In accordance with the simulations no evidence of a separation of $\mathrm{Ba}$ and $\mathrm{Ca}$ atoms on the common positions could be obtained.

The beam sensitivity of the domains with the $\mathrm{Ba}_{19} \mathrm{Li}_{44}$ type structure appears even stronger than that of $\mathrm{Li}_{33.3} \mathrm{Ba}_{13.1} \mathrm{Ca}_{3}$-type. Fig 5 shows the comparison of the projected potential, a high resolution picture along [100] and a $\mathrm{Ba}$ substructure of $\mathrm{Ba}_{19} \mathrm{Li}_{44}$-type. For $\Delta \mathrm{f}=-35 \mathrm{~nm}$ the agreement between potential and high resolution image is obvious. The bright dots correlate with the Ba positions (circles in Fig 5a), and the positions of the octahedral $\mathrm{Ba}_{6}$ cluster building perpendicular crossings could be clearly identified.

In one crystallite an intergrowth of a domain with the $\mathrm{Ba}_{19} \mathrm{Li}_{44}$-type structure and one unknown and more complex structure could be observed (Fig 6). The zone axis orientation of the domain with $\mathrm{Ba}_{19} \mathrm{Li}_{44}$ structure is [110] cf. Fourier transform in Fig 6 (above right). In the left section of the image contrast variations occur and the Fourier transform (Fig. 6 above left) shows 
additional reflections, cf. arrows. Both phases join congruently, so that the intensities of the basic $\mathrm{Ba}_{19} \mathrm{Li}_{44}$-type remain in the Fourier transformation of the complex phase. The translation period of $\mathrm{Ba}_{19} \mathrm{Li}_{44}$ type along [-110]* is formally quadrupled, however, a superstructure could not be identified unambiguously owing to absence of any clear separation between main and superstructure intensities from the Fourier transformation.

EDX analyses show that both domains have small, even though significant, calcium content. According to this the above-described lattice contractions are within detection limit. A lattice parameter of $23.2 \AA$ can not be assigned to any known phase. The new phase proves to be extremely beam-sensitive, so that probably only the combination of systematic syntheses and $\mathrm{X}$-ray investigations can reveal its true nature.

The structural transformations under irradiation were investigated for the crystallites of different phases observed here. Continuous irradiation leads, depending on the existing structure type, to various defined products. Crystals of $\mathrm{Li}_{33.3} \mathrm{Ba}_{13.1} \mathrm{Ca}_{3}$ decompose irreversibly to domains with bcc structure. For the $\mathrm{Ba}_{19} \mathrm{Li}_{44}$-type a disordered structure variant formed, showing diffuse intensities in addition to the main structure intensities in the diffraction diagram. As a rule the Ba:Ca ratio increases during irradiation, and finally domains with bcc structure are observed.

The decomposition of the crystals with $\mathrm{Ba}_{19} \mathrm{Li}_{44}$-type structure proceeds without a change of the particle shape and main structural motives. PED diagrams show a loss of the structural complexity after irradiation owing to fading of the intensities in the HOLZ (Fig. 7). However, intensities of $\mathrm{Ba}_{19} \mathrm{Li}_{44}$-type remain also after irradiation in the zero order Laue zone where additionally structured diffuse streaks occur. The streaks are parallel to [-110]* with respect to the $\mathrm{Ba}_{19} \mathrm{Li}_{44}$-type. It has to be clarified whether the irradiated phase represents a disordered variant of $\mathrm{Ba}_{19} \mathrm{Li}_{44}$-type, which could be a high temperature modification. 


\section{Conclusions}

Two previously discovered and structurally characterized compounds $\mathrm{Ba}_{19} \mathrm{Li}_{44}$ and $\mathrm{Li}_{33.3} \mathrm{Ba}_{13.1} \mathrm{Ca}_{3}$ were investigated by transmission electron microscopy. Their crystal structures were confirmed, however both were found with variable $\mathrm{Ca}$ content. These compounds are strongly temperature and beam sensitive, and the strategies to avoid beam damage during the measurements have to be improved. A first step could be the embedding of the sample into a conductive polymer. The present investigation indicates that particles with direct contact to the copper grid hardly transform. In further investigations, in order to reduce beam damage, a low temperature sample holder in combination with the PED technique could be beneficial, in particular, as this diffraction technique is not sensitive to the sample vibrations occurring under the settings of the low temperature experiments. 
Fig. 1: a) SAED b) PED diagrams of a grain to be assigned to $\mathrm{Li}_{33.3} \mathrm{Ba}_{13.1} \mathrm{Ca}_{3}$-type, and c) simulated PED diagram for the $\mathrm{Li}_{33.3} \mathrm{Ba}_{13.1} \mathrm{Ca}_{3}$-type, zone axis [-25-1].

Fig. 2: Experimental und simulated PED diagrams for the $\mathrm{Ba}_{19} \mathrm{Li}_{44}$-type a) zone axis [100], b) zone axis [110].

Fig. 3: HRTEM of $\mathrm{Li}_{33.3} \mathrm{Ba}_{13.1} \mathrm{Ca}_{3}$-type crystal, zone axis orientation [100]. a) Projected potential (scaling compared to experimental images approx. $234 \%$ ). b) Heavy atom substructure. c) Simulated (left, focus specified, $t=10 \mathrm{~nm}$ ) and experimental (right) high resolution images.

Fig. 4: HRTEM of the $\mathrm{Li}_{33.3} \mathrm{Ba}_{13.1} \mathrm{Ca}_{3}$-type crystal, zone axis orientation [-25-1]. a) Projected potential (scaling compared to experimental images approx. $264 \%$ ). b) Simulated (small squares, focus specified, $t=15.4 \mathrm{~nm}$ ) and experimental high resolution images.

Fig. 5: High resolution microscopy of the $\mathrm{Ba}_{19} \mathrm{Li}_{44}$-type crystals, zone axis orientation [100]. a) Projected potential (scaling compared to experimental images approx. $166 \%$ ). b) Simulated (top, focus specified, $t=9.8 \mathrm{~nm}$ ) and experimental (bottom) high resolution images. c) $\mathrm{Ba}_{13}$ cluster and Ba substructure of $\mathrm{Ba}_{19} \mathrm{Li}_{44}$ ( $\mathrm{Ba}_{17}$ clusters are marked as crosses).

Fig. 6: HRTEM of one complex structure variant of the $\mathrm{Ba}_{19} \mathrm{Li}_{44}$ type. Above: Fourier transformation of the region with (left) and without (right) superstructure. Below: high resolution image (upperfocus).

Fig. 7: Transformation of the crystal with the $\mathrm{Ba}_{19} \mathrm{Li}_{44}$ structure during the irradiation. Left: PED diagram before the transformation, zone axis [110], right: after the transformation. 
a)
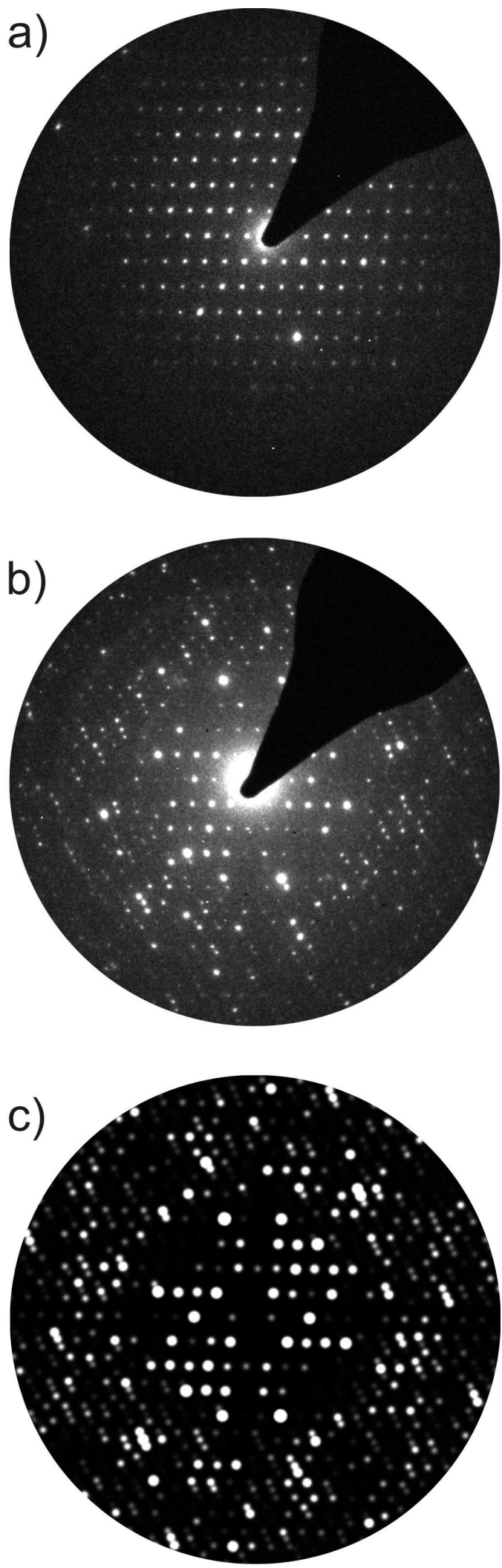


\section{Page 11 of 25}

a)
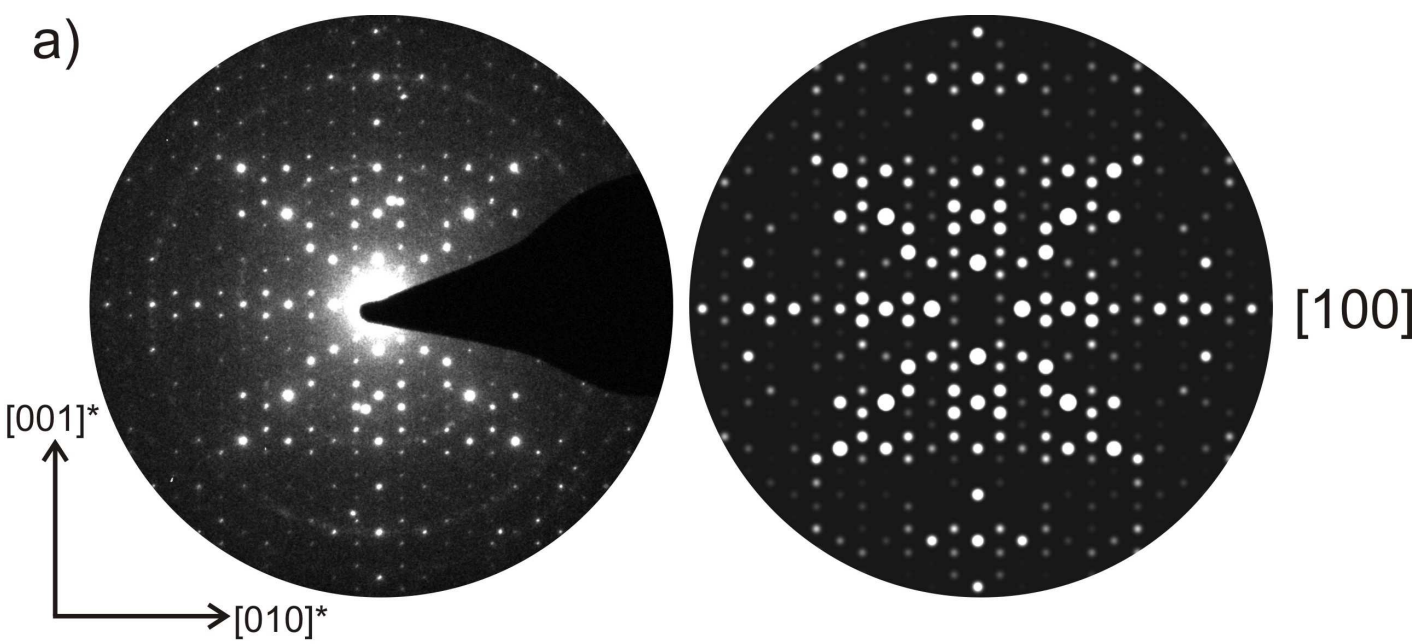

b)
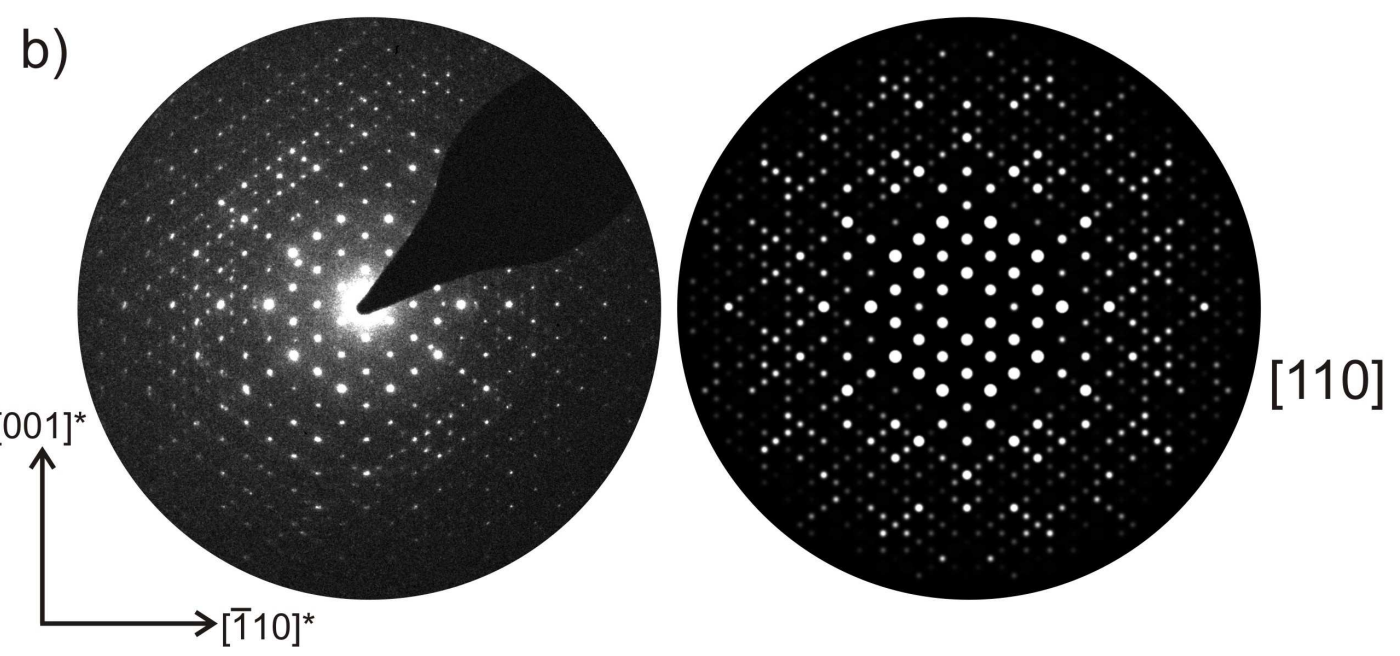
1

2

43

5

6

7

8

9

10

11

12

13

14

15

16

17

18

19

20

21

22

23

24

25

26

27

28

29

30

31

32

33

34

35

36

37

38

39

40

41

42

43

44

45

46

47

48

49

50

51

52

53

54

55

56

57

58

59

60 


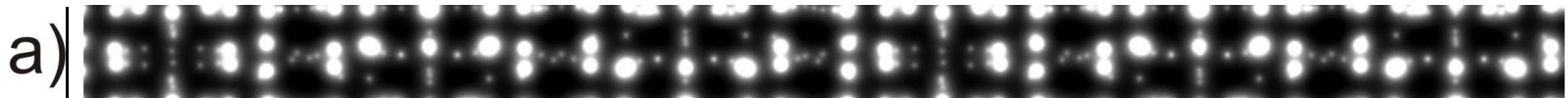

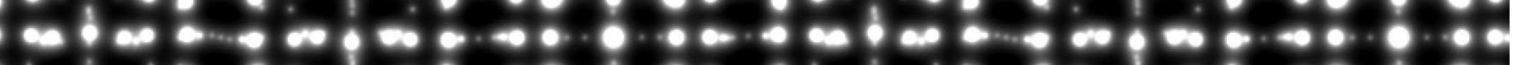

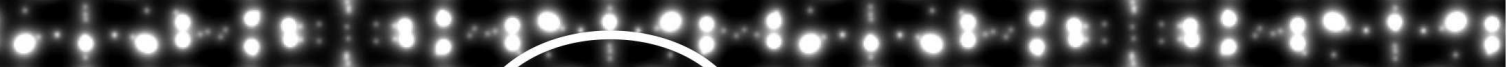

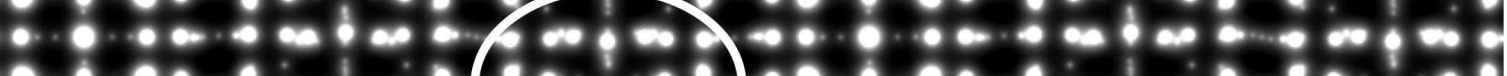

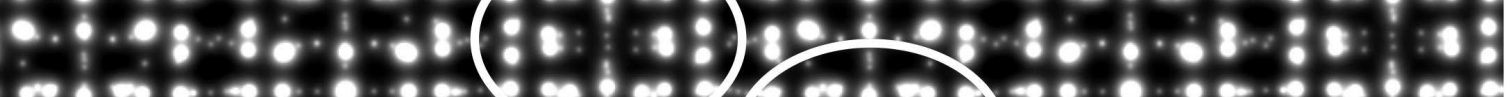

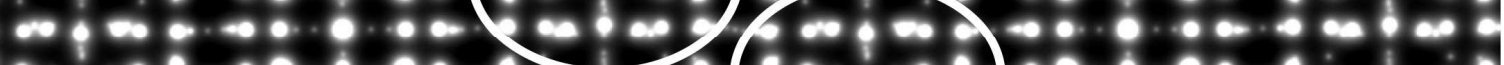

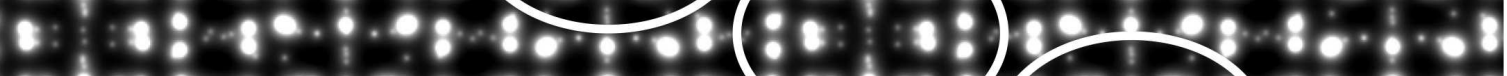

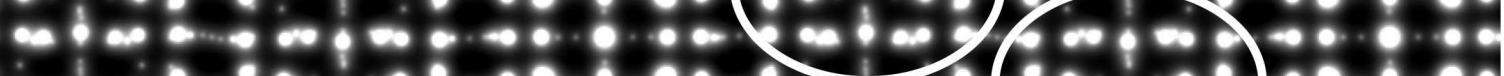
¿.

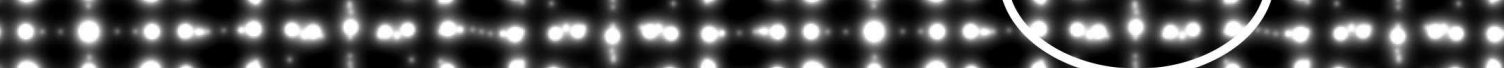

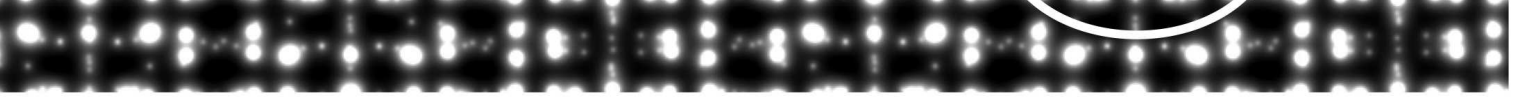

b)

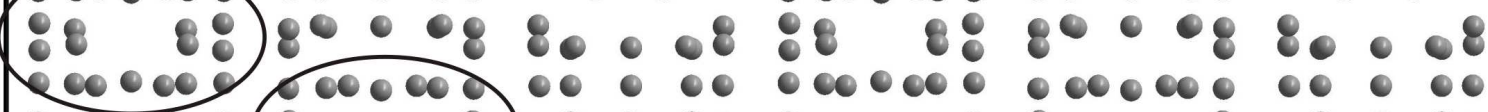

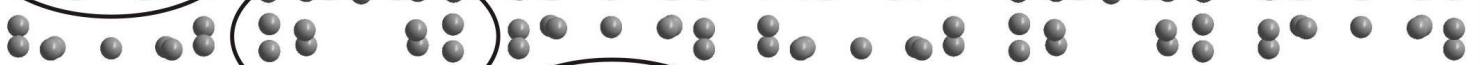

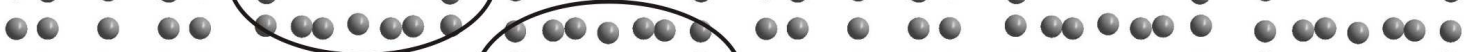

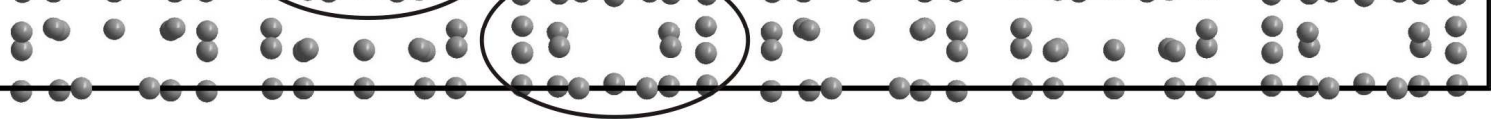

C) $\Delta f=+35 n m$
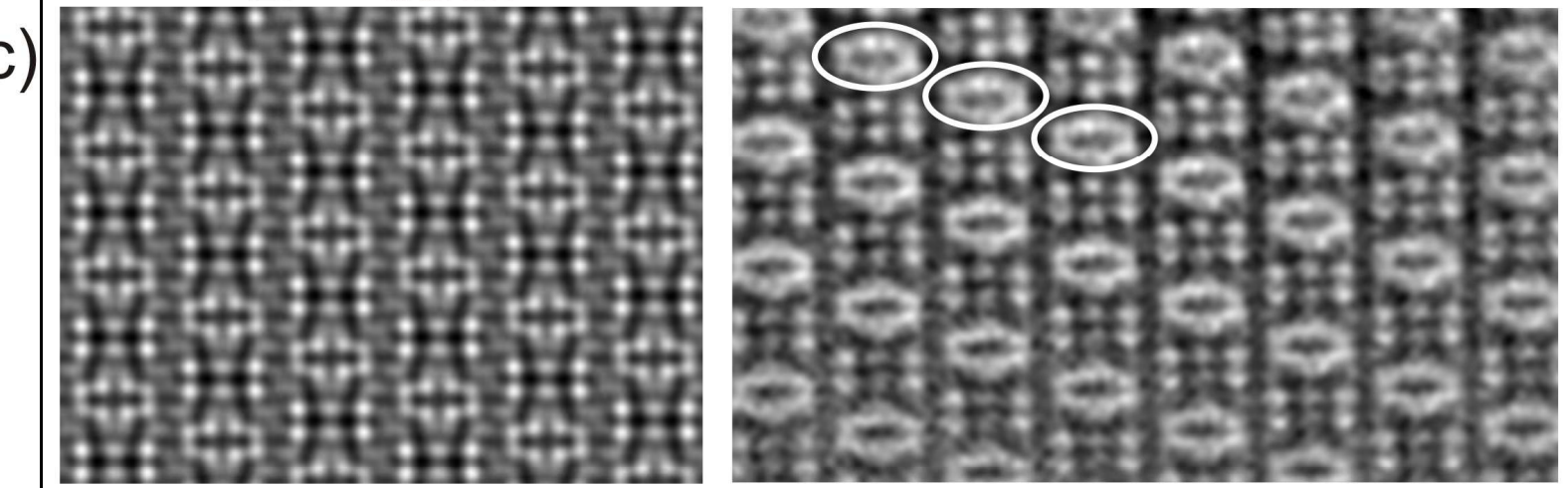

$$
\Delta f=-15 n m
$$
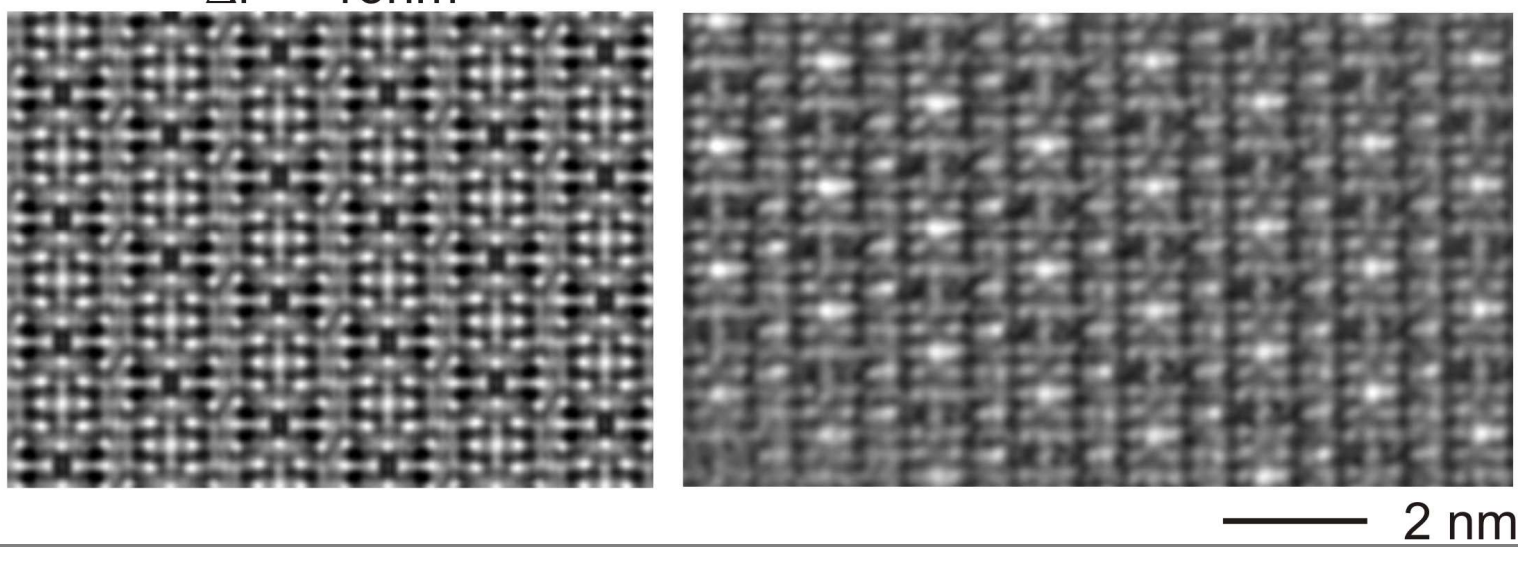

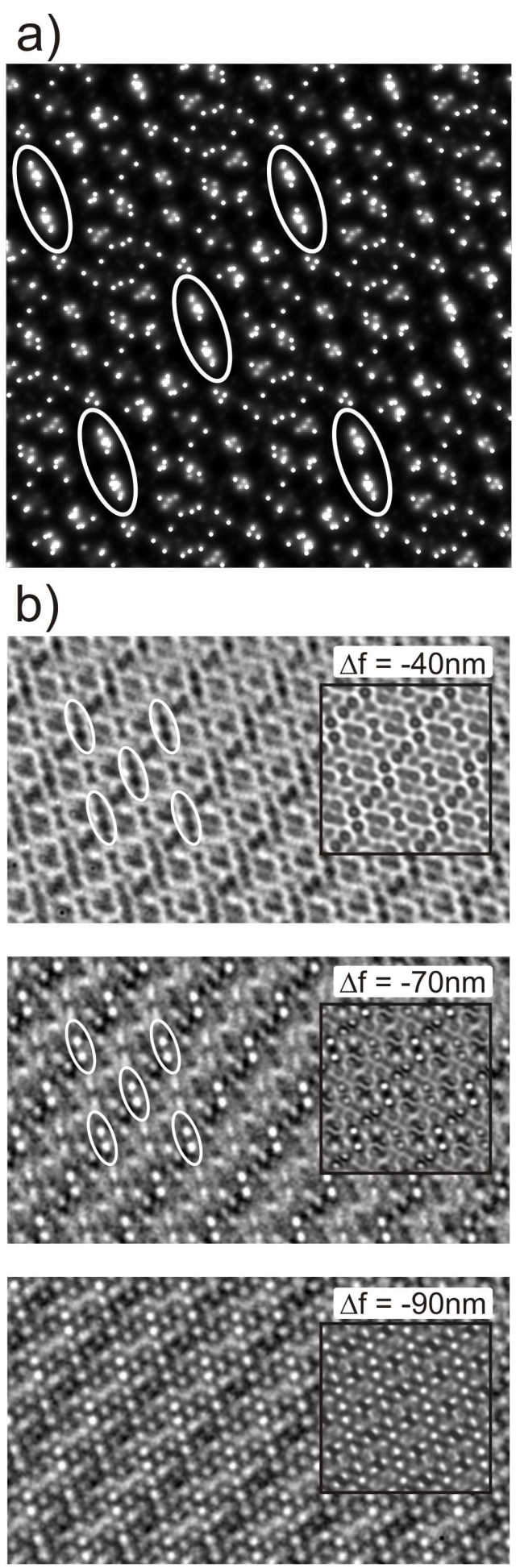
$2 \mathrm{~nm}$ 
a)

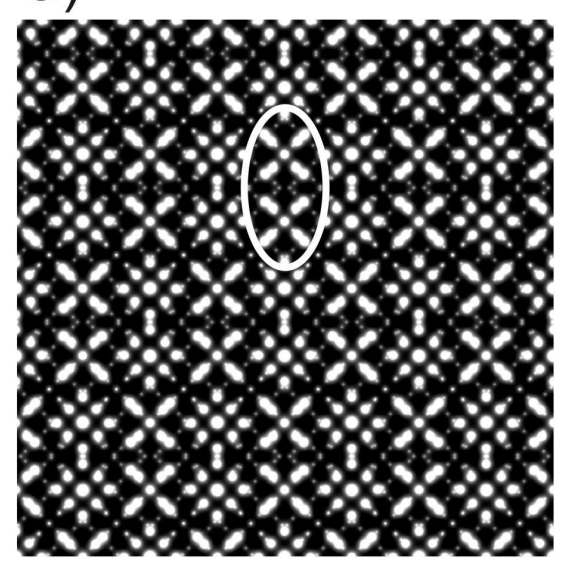

b)

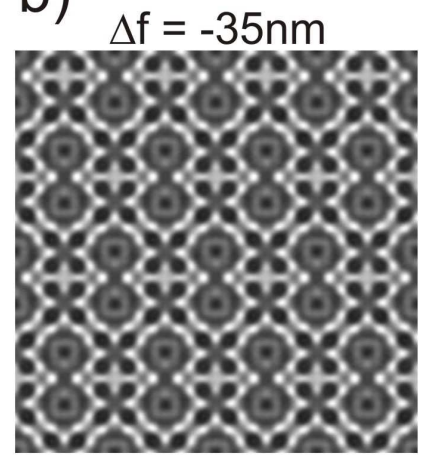

c)
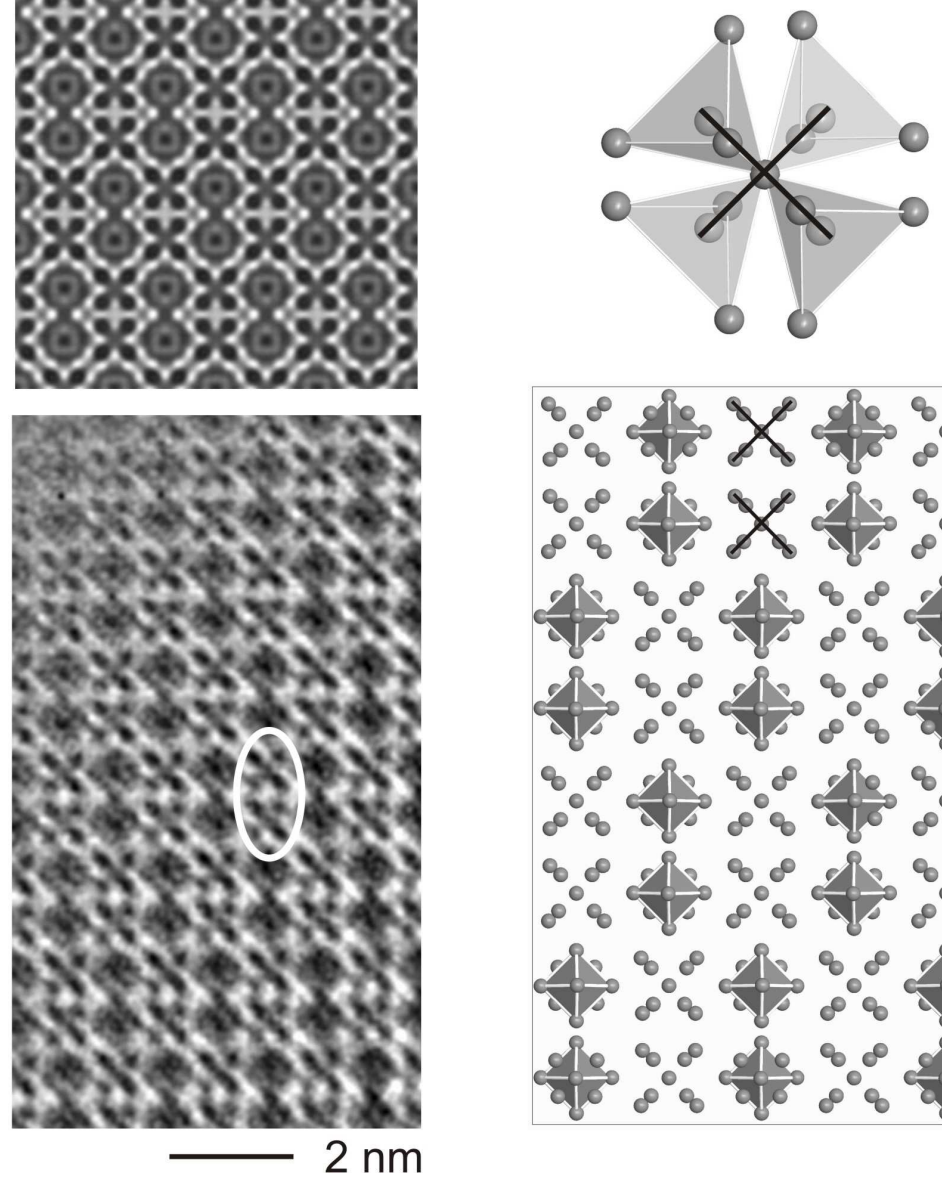

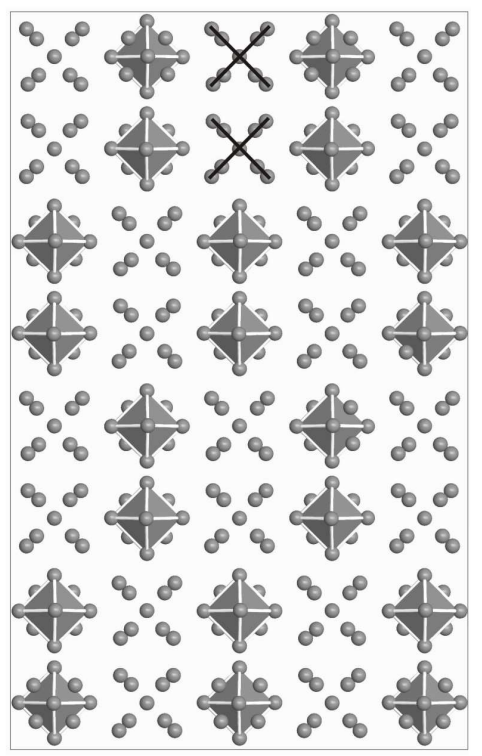


6

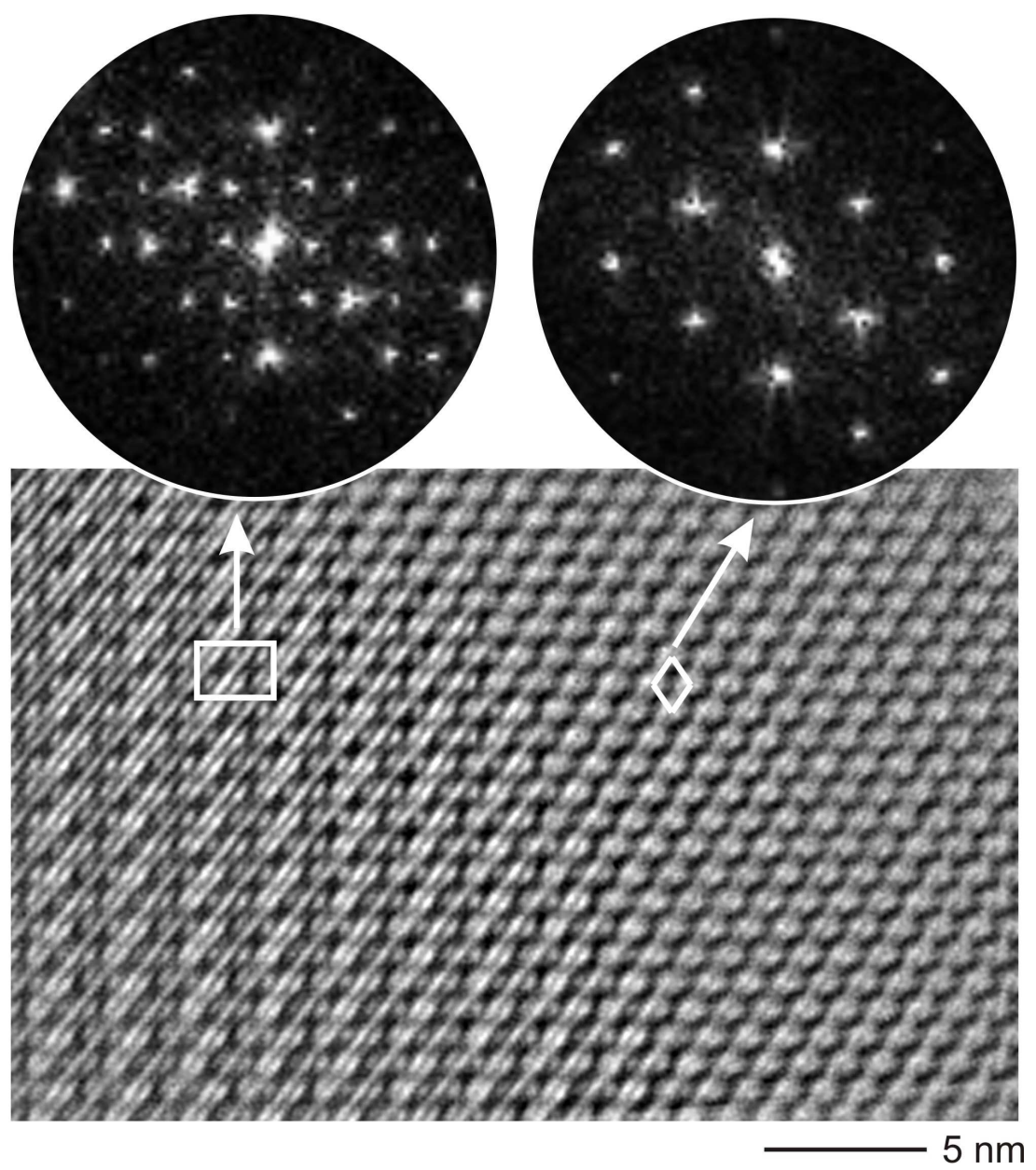

Wiley-VCH 


\section{Page 17 of 25}

7
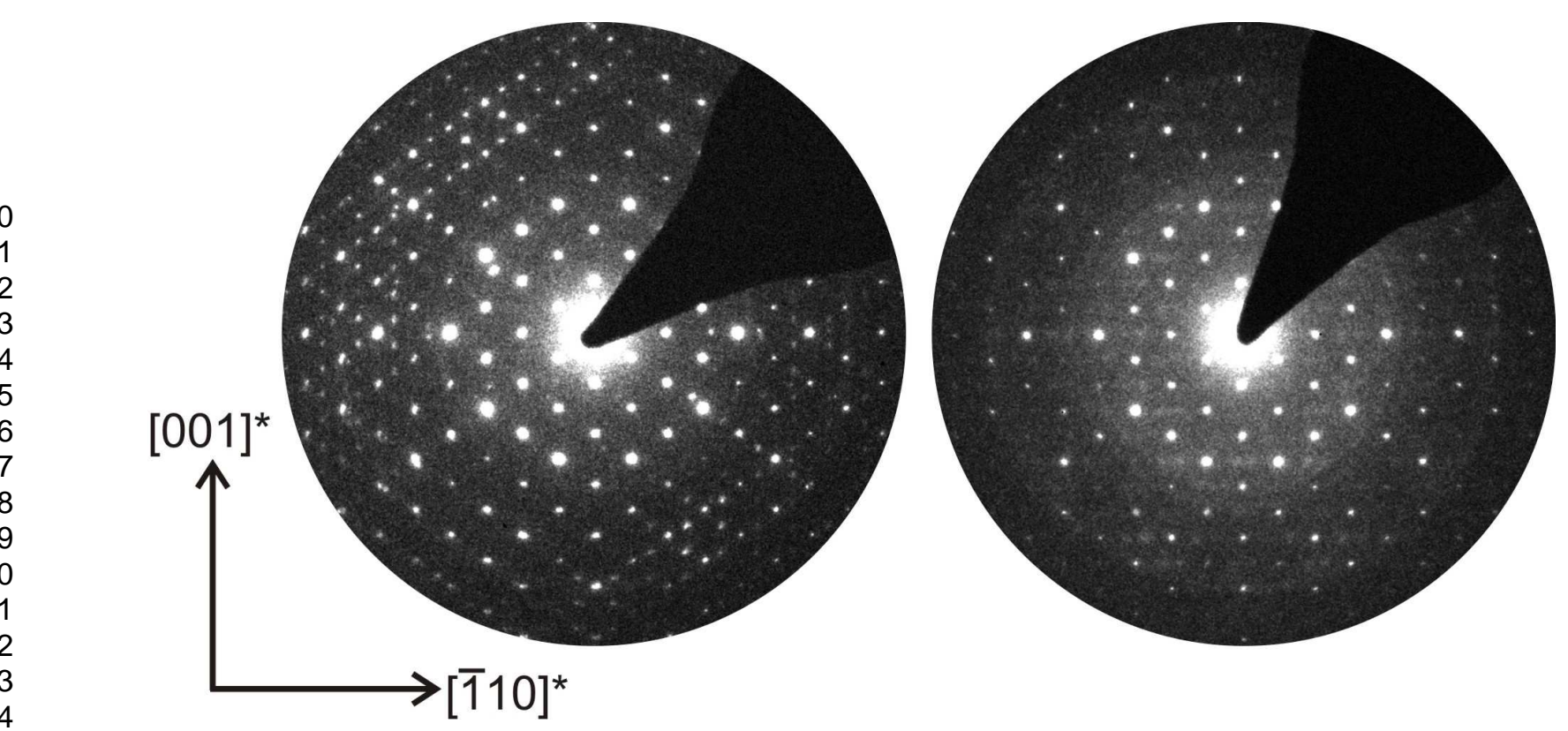

1
2
3
4
5
6
7
8
9
10
11
12
13
14
15
16
17
18
19
20
21
22
23
24
25
26
27
28
29
30
31
32
33
34
35
36
37
38
39
50
59
50
40
40
43
40
48
49
50
51
52

1

4

5
6
17

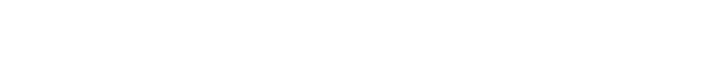


[1] R. Nesper, G. Miller J Alloys Compds, 1993, 197, 109-121.

[2] D. Fischer, M. Jansen Z Anorg Allg Chem, 2003, 629, 1934-1936.

[3] F. Wang, A. King, F. Kanda J Phys Chem, 1962, 66, 2142-2145.

[4] V. Smetana, V. Babizhetskyy, C. Hoch, A. Simon Z Kristallogr NCS, 2006, 221, 434.

[5] V. Smetana, V. Babizhetskyy, G. Vajenine, C. Hoch, A. Simon Inorg Chem, 2007, 46, 5425-5428.

[6] G. Snyder, A. Simon Z Naturforsch B, 1994, 49, 189-192.

[7] G. Snyder, A. Simon J Chem Soc Dalton Trans, 1994, 1159-1160.

[8] V. Smetana, V. Babizhetskyy, G. Vajenine, A. Simon Angew Chem, 2006, 118, 6197-6200.

[9] V. Smetana, V. Babizhetskyy, C. Hoch, A. Simon J Solid State Chem, 2007 180, 3302-3309.

[10] P. Jeitschko, A. Simon, R. Ramlau, Hj. Mattausch Z Anorg Allg Chem 1997, 623, 1447-1454

[11] R Vincent, P.A Midgley Ultramicroscopy 1994, 53, 271-282

[12] J.Gjonnes, V.Hansen, A. Krerneland Microscopy and Microanalysis 2004, 10, 16-20

[13] T. Weirich, J. Portillo, G. Cox, H. Hibst, S. Nicolopoulos Ultramicroscopy 2006, 106, 164-175

[14] M. Gemmi, X. Zou, S. Hovmoller, A. Migliori, M. Vennstrom Y. Andersson Acta Cryst 2003, A59, 117-126

[15] C. Own PhD thesis, Northwestern University Evanston Illinois December 2005.

[16] Emaps 1.0, AnaliTEX 2002-2007.

[17] Crisp 2.1a, Calidris, Manhemsvägen 4, Sollentuna, Sweden, 2007.

[18] P. Goodman, A. Moodie Acta Cryst 1974, A30, 280-290.

[19] J. Cowley, A. Moodie Acta Cryst 1957, 10, 609-619.

[20] P. Stadelmann Ultramicroscopy 1987, 21, 131-146.

[21] O. Scherzer J Appl Phys 1949, 20, 20-29. 


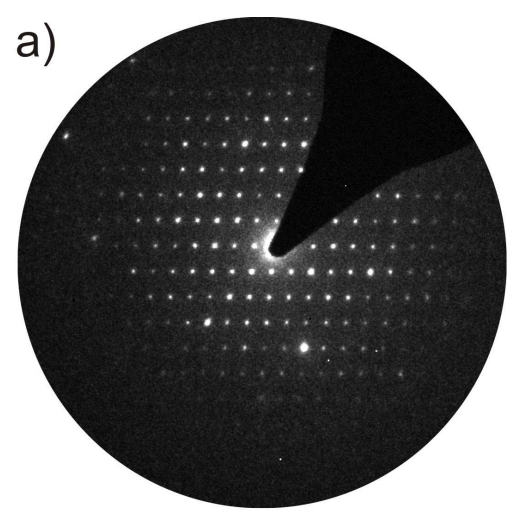

b)

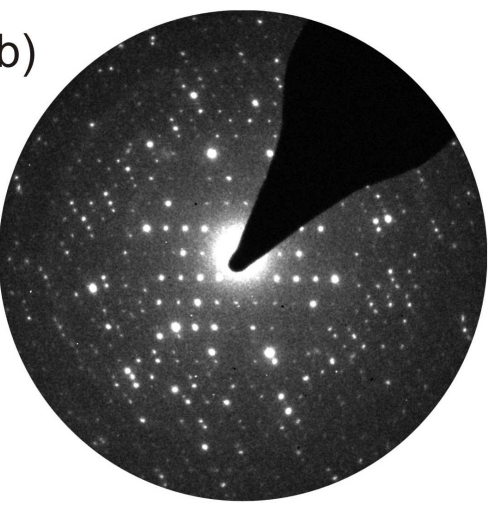

c)

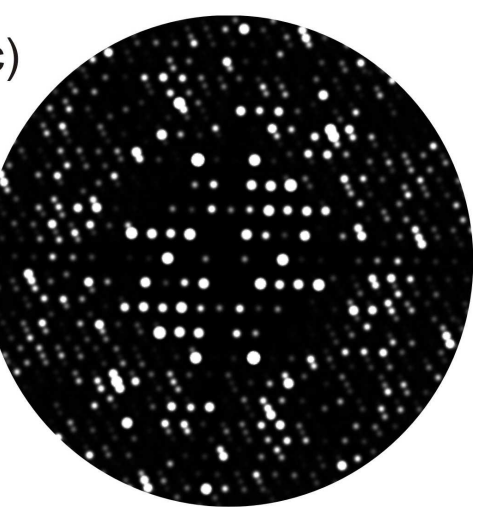

a) SAED b) PED diagrams of a grain to be assigned to Li33.3Ba13.1Ca3-type, and c) simulated PED diagram for the Li33.3Ba13.1Ca3-type, zone axis [-25-1]. $90 \times 285 \mathrm{~mm}(300 \times 300 \mathrm{DPI})$ 

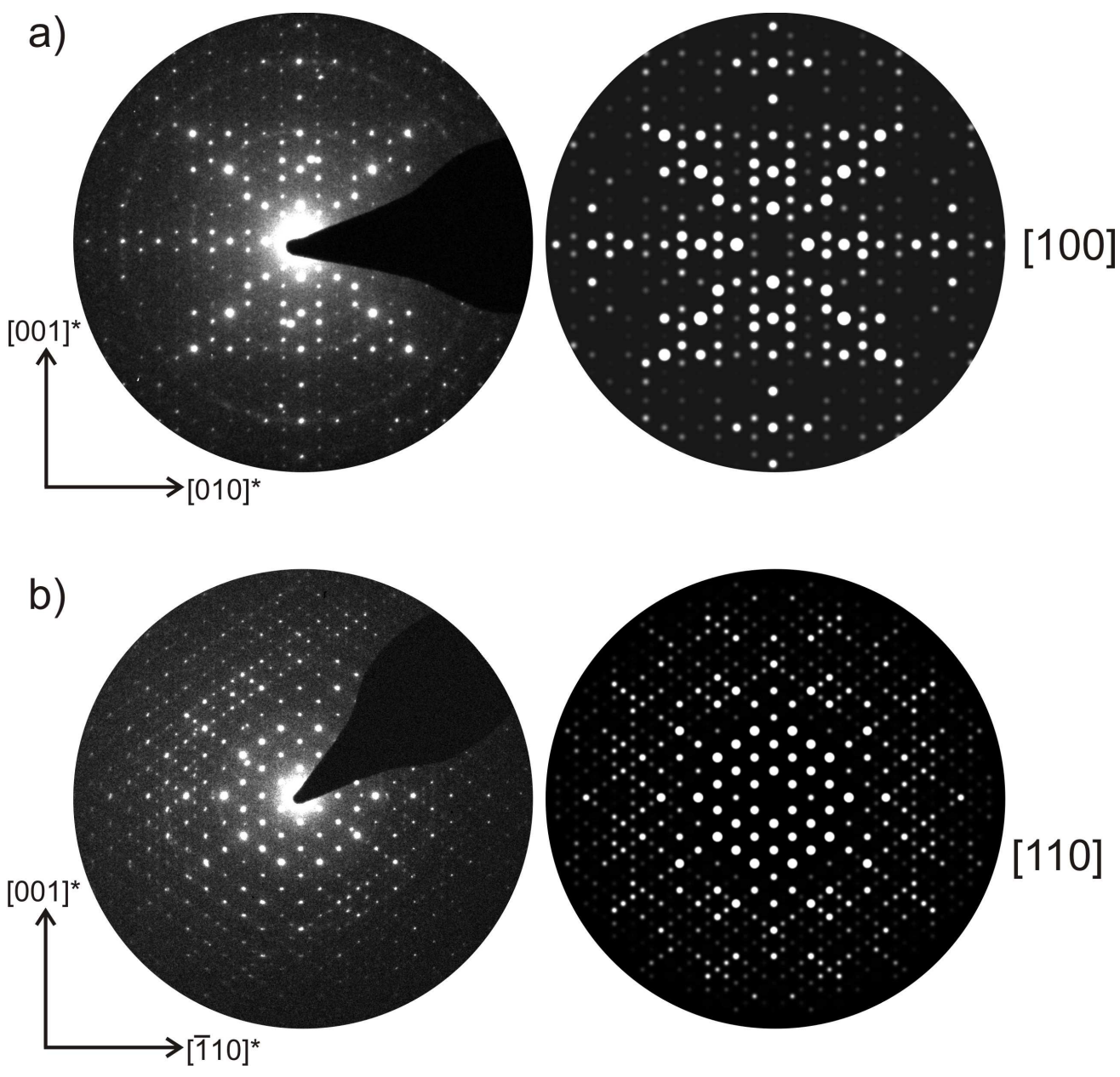

Experimental und simulated PED diagrams for the Ba19Li44-type a) zone axis [100], b) zone axis [110]. $217 \times 206 \mathrm{~mm}(300 \times 300 \mathrm{DPI})$ 


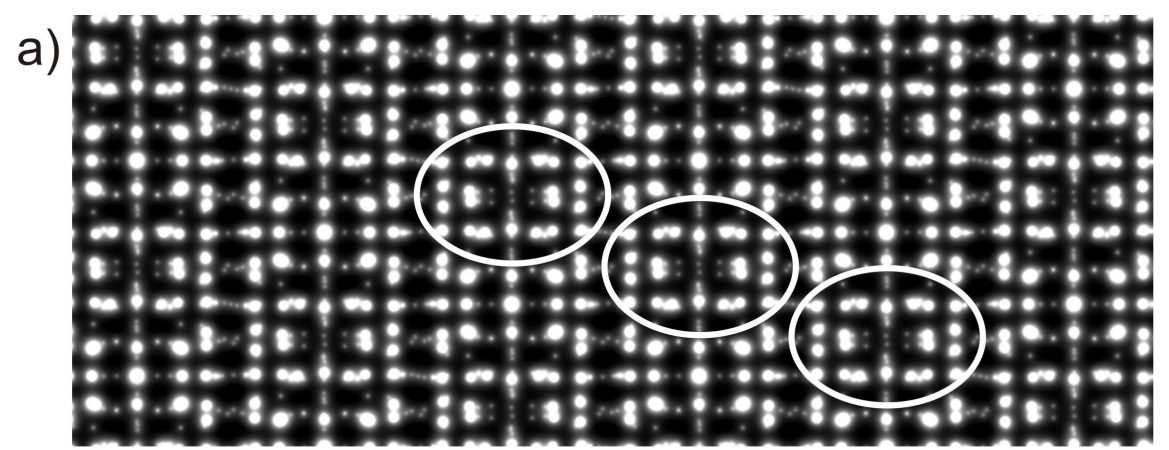
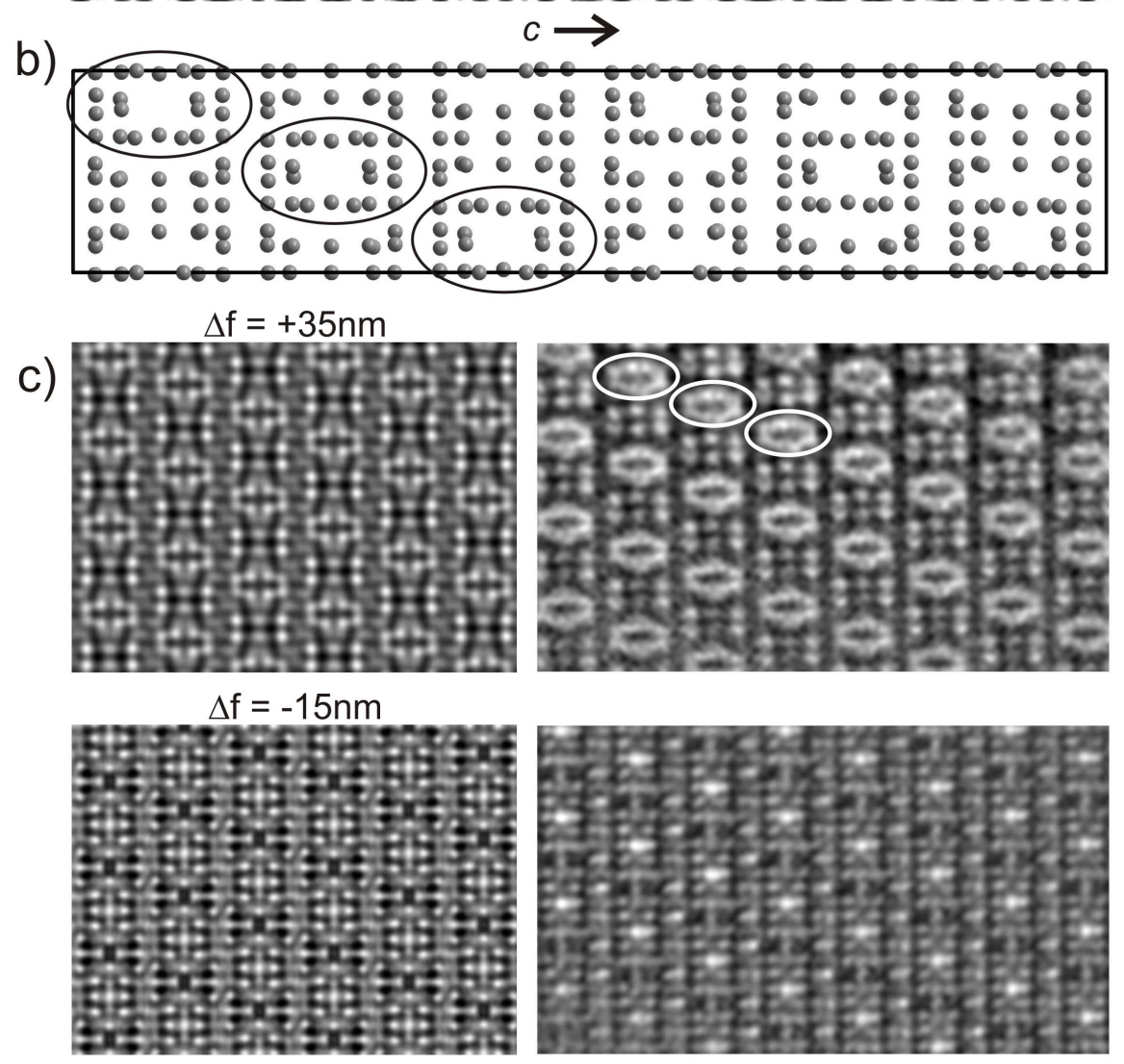

$194 \times 266 \mathrm{~mm}(300 \times 300$ DPI $)$ 


\section{a)}

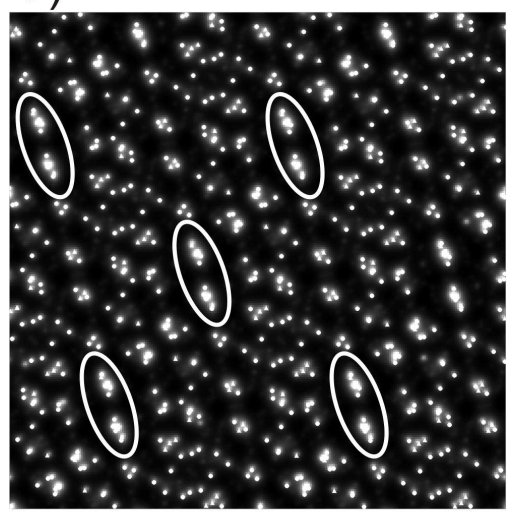

b)
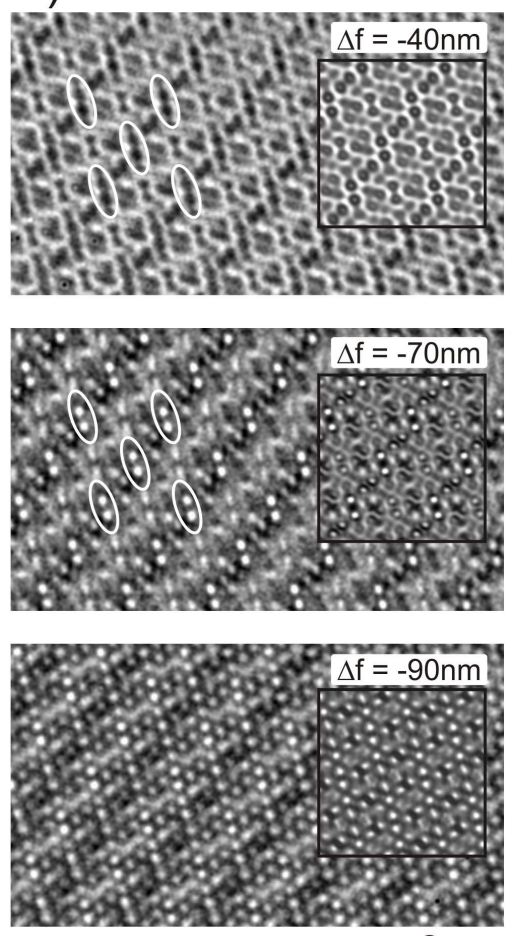

$-2 \mathrm{~nm}$

HRTEM of the Li33.3Ba13.1Ca3-type crystal, zone axis orientation [-25-1]. a) Projected potential (scaling compared to experimental images approx. $264 \%$ ). b) Simulated (small squares, focus specified, $\mathrm{t}=15.4 \mathrm{~nm}$ ) and experimental high resolution images. $83 \times 262 \mathrm{~mm}(300 \times 300$ DPI $)$ 
a)

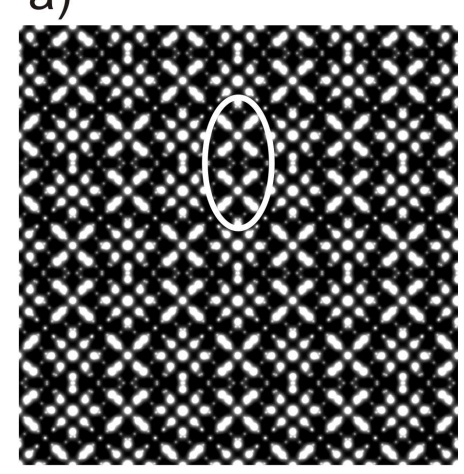

b)
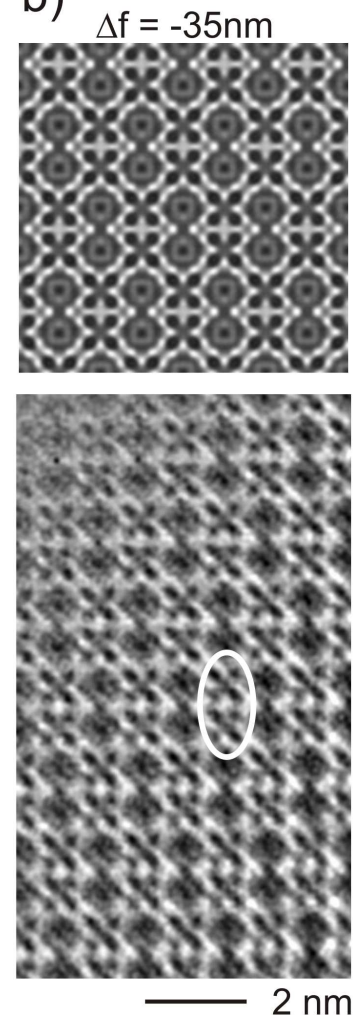

c)
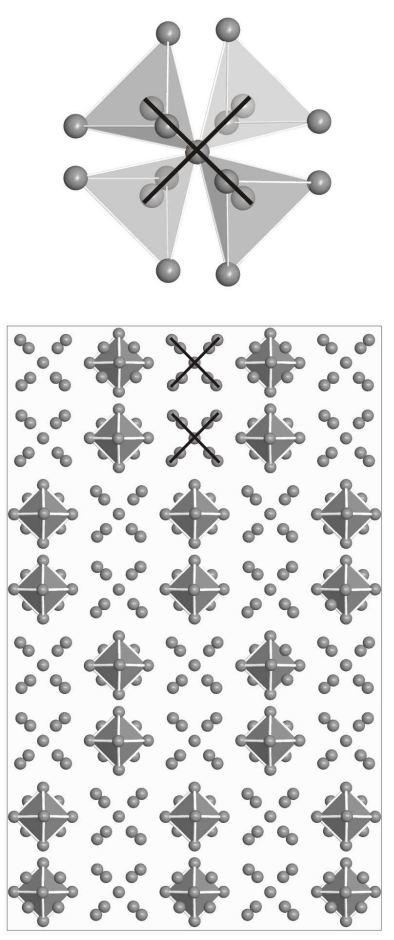

High resolution microscopy of the Ba19Li44-type crystals, zone axis orientation [100]. a) Projected potential (scaling compared to experimental images approx. $166 \%$ ). b) Simulated (top, focus specified, $\mathrm{t}=9.8 \mathrm{~nm}$ ) and experimental (bottom) high resolution images. c) Ba13 cluster and $\mathrm{Ba}$ substructure of Ba19Li44 (Ba17 clusters are marked as crosses). $139 \times 270 \mathrm{~mm}(300 \times 300 \mathrm{DPI})$ 


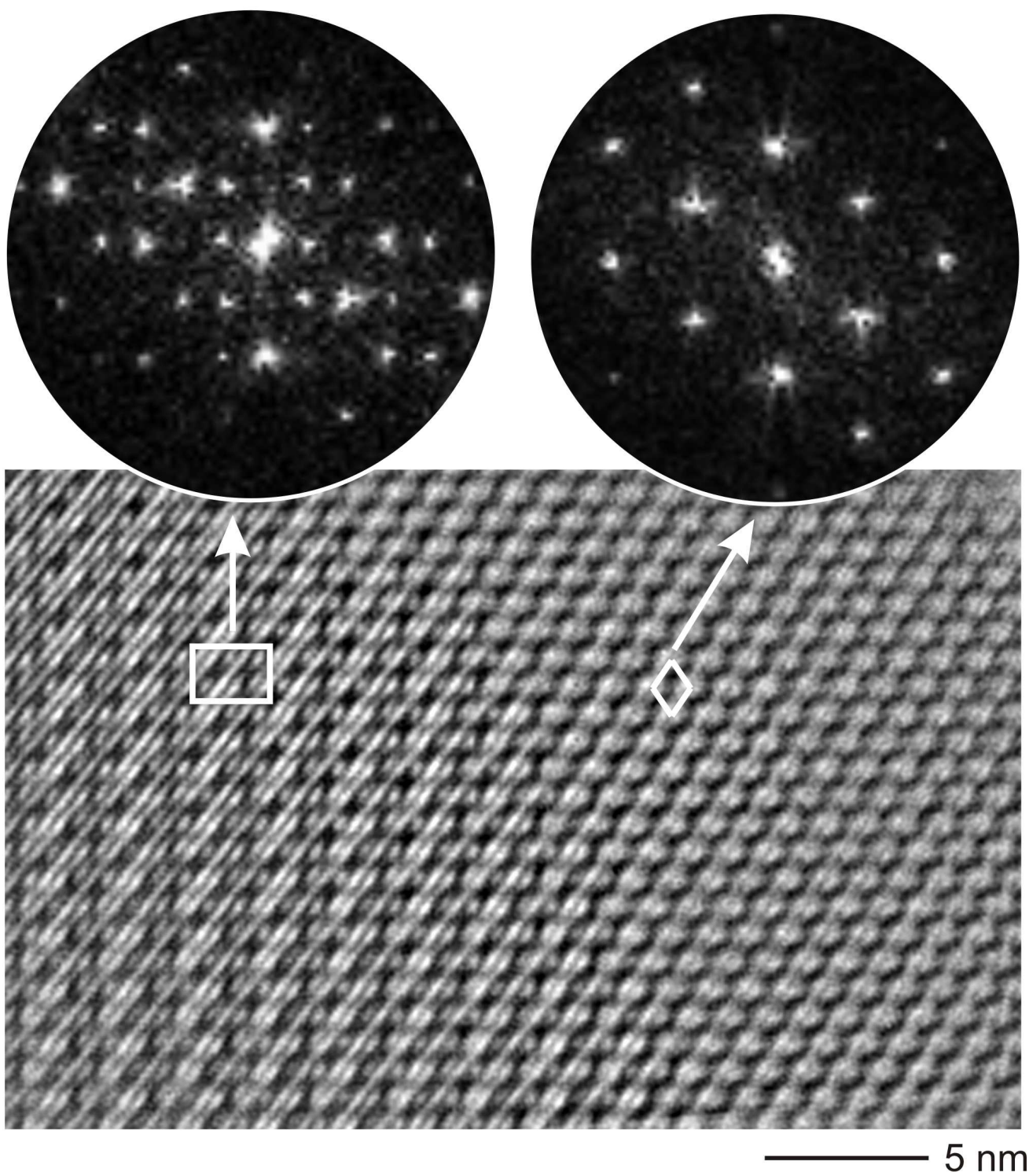

HRTEM of one complex structure variant of the Ba19Li44 type. Above: Fourier transformation of the region with (left) and without (right) superstructure. Below: high resolution image (upperfocus). $169 \times 193 \mathrm{~mm}(300 \times 300 \mathrm{DPI})$ 


\section{Page 25 of 25}
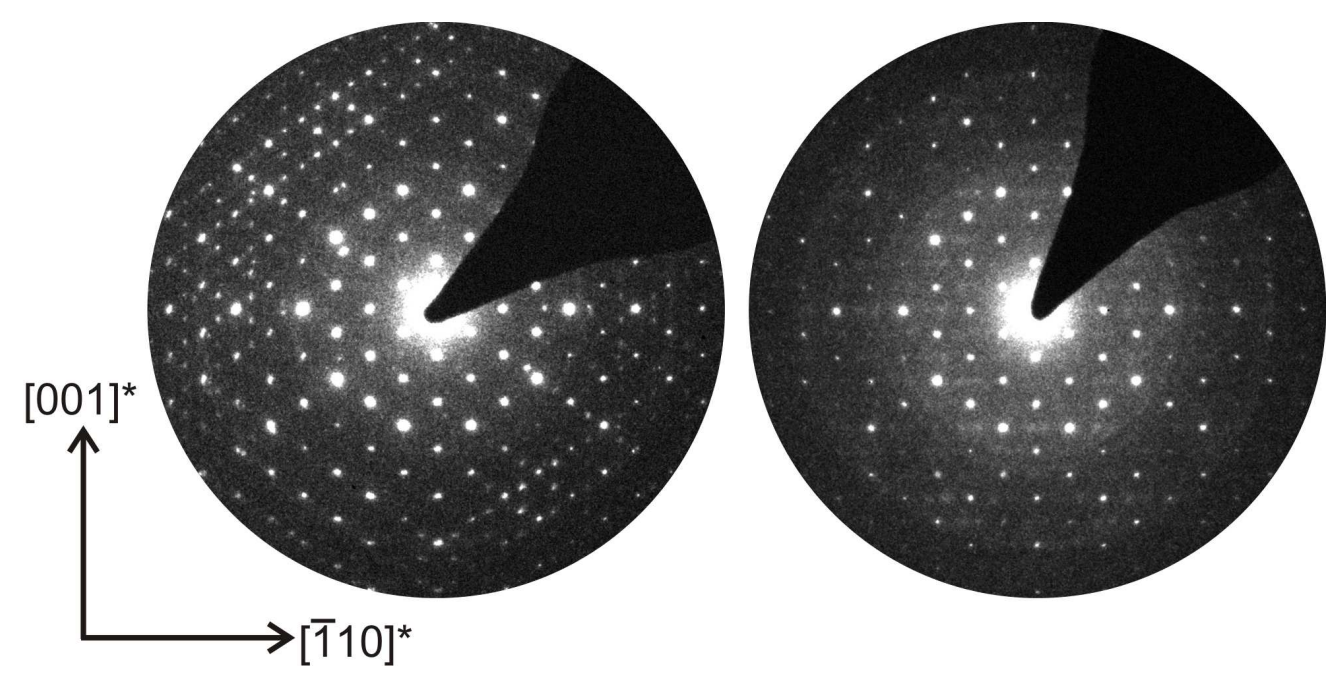

Transformation of the crystal with the Ba19Li44 structure during the irradiation. Left: PED diagram before the transformation, zone axis [110], right: after the transformation. $167 \times 82 \mathrm{~mm}(300 \times 300 \mathrm{DPI})$ 